\title{
World Bobsleigh Tracks: from Geometry to the Architecture of Sports Facilities
}

\author{
Mariya Komarova ${ }^{1}$
}

Published online: 3 July 2017

(C) Kim Williams Books, Turin 2017

\begin{abstract}
The object of this research is the integration of innovative technologies with the architecture of modern sports facilities. The article describes the use of new methods in the architectural and structural design and landscaping of unique Olympic sports infrastructures, namely bobsleigh, skeleton and luge track complexes. A brief historical overview of winter sled sports is made, in which the geometric analysis of tracks, their architectural styles, and land planning compositions are studied. As a recent example of the architecture of sport facilities, the article presents the author's original contribution on the bobsleigh track of Sochi, built for the Winter Olympics, 2014. In addition, the question about using the bobsleigh tracks in the off season is also examined.
\end{abstract}

Keywords Geometry · Structural systems · Modules · Engineering · Landscape architecture

\section{Introduction: Origin and Development of Bobsleigh}

Sledding on snow or ice has long been considered winter folk fun in many northern countries. For example, giant ice mountains with the height of 12-14 m were specially built to sled down in Russia on the Pancake week (end of Februarybeginning of March). They became centers of festivals, fairs were created around them, swings, roundabouts and booths were set, and various amusements were held. Mountains were built in all cities and large villages at the expense of the city budget, but more often merchants, showmen or inhabitants themselves clubbed

Mariya Komarova

mariya.komarova@polito.it

1 Department of Architecture and Design, Politecnico di Torino, Viale Pier Andrea Mattioli, 39, 10125 Turin, Italy 
together to pay for their construction. As a rule, the mountains were built in pairs, opposite each other, so that their slopes were parallel. Often these impressive structures were crowned by towers or pavilions on platforms from which the descent started. The length of the descent could be 100-140 m, so one could gain speed. They decorated mountains with flags, trees, and sometimes wooden sculptures (Fig. 1). The police strictly followed the order of their construction; they were interested in safety measures: the reliability of facilities, availability of railings and fences, and without protruding nails, etc. Crowds of people gathered to watch the sledding from the mountain, and the active trade was near to it. Here they traded hot tea, a variety of sweets, candied fruits, nuts, cakes, pies and pancakes, that were baked on site or brought from nearby taverns.

Thus, people's fun — sledding from the mountain — gradually transformed into the modern kind of winter sports: bobsleigh, skeleton and luge. If the last two are types of direct sledding (skeleton-a person rides a small sled down a frozen track while lying face down and head forward; luge-one or two persons ride a small sled down a frozen track while lying face up and feet-first), the main competitor in bobsleigh is a vehicle-the bobsled. The prototype of the modern sports equipment was a construction made of metal runners, united by the board, and furnished with steering (Fig. 2). In 1897, the enthusiasts of a newly invented kind of sport-bobsleigh, riding down a frozen track in the long sled-organized a bobsleigh club in St. Moritz. At the same time there was also a toboggan club (now skeleton) in St. Moritz.

Modern sports bobsled (bob) can be two-man or four-man; the sled comprises an articulated frame construction of two halves closed by a streamlined body made of composite carbon materials. The articulation makes it possible to pass curves of

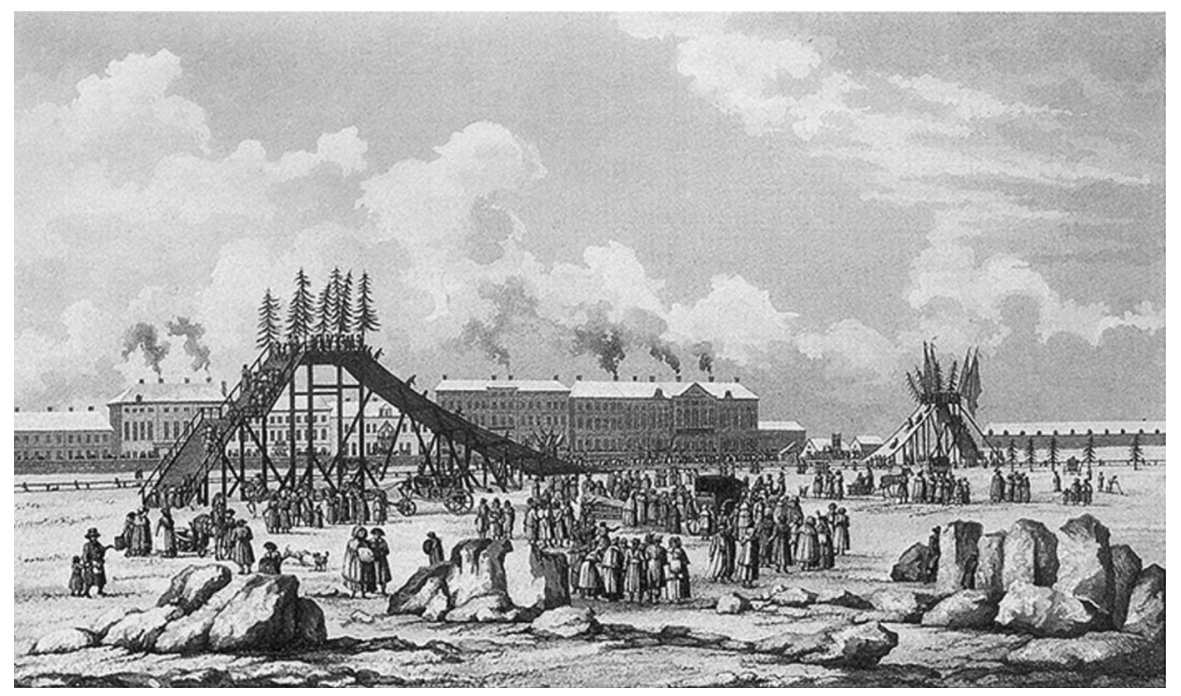

Fig. 1 Icy Mountains on the Neva River. Etching, aquatint by Michel-FransoisDamame-Demartrais, 1813. Source: Paris, Bibliothèque Nationale De France. (Image is in the public domain, published prior to 1923) 


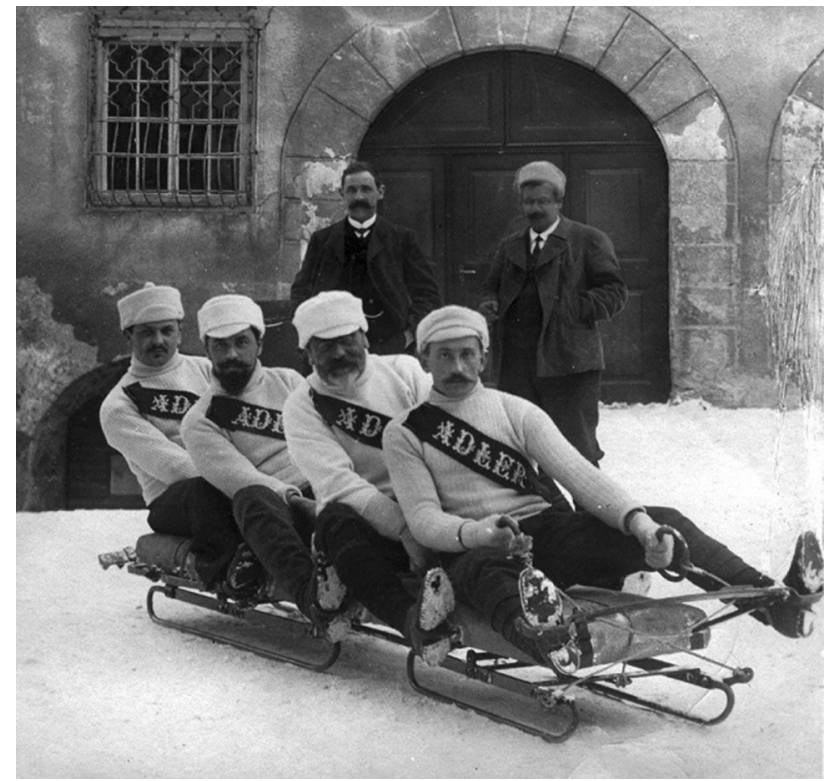

Fig. 2 Swiss bobsleigh team from Davos, 1910. Source: Retrieved 10 November 2016 from https://en. wikipedia.org/wiki/Bobsleigh\#/media/File:Bobfahrer_Davos.jpg (public domain)

track clinging to the ice with all four runners. The pilot drives with the help of steering rods that must be used very precisely and smoothly, otherwise there is a risk of losing control. The profile and geometry of the runners, hardness of alloys, hardening and surface treatment methods are of great importance to achieve the best results in competition. There are special scientific groups that are engaged in the design, selection of materials and testing of this fancy sports equipment, all the geometric and technical characteristics of which are strictly regulated by the International Bobsleigh Rules. The competitions in bobsleigh, skeleton and luge are held on special tracks; to design them in the first place one must know the sizes of the sports-bob and sled. All the main dimensions and constructive elements of the bobs are fixed. The gauge (center to center of opposite runners) is the same for the front and rear runners, $670 \pm 5 \mathrm{~mm}$. The distance from the center of the front axle to the center of the rear axle (referred to as the plane of symmetry of the bob): $1690 \pm 30 \mathrm{~mm}$ (two-man bob), $2130 \pm 30 \mathrm{~mm}$ (four-man bob). Other dimensions are also regulated and all of them can be found in the International Bobsleigh Rules 2015-IBSF (IBSF 2015).

The first track for open bobsleds was specifically built in 1904 in Switzerland, between St. Moritz and Celerina; it is considered the oldest bobsleigh track in the world. It is the only track of natural origin preserved today, it is renewed every year and, at the same time, there is no refrigerating facility. More than 35 World Championships and two Winter Olympics - in 1924 and 1948 - have been held on it since its foundation. From the beginning of the twentieth century until the 1980s, the Angelini family had been responsible for the annual construction of the track, and 
three generations of the family were engaged in this work. In 1985 Louis Prantl took over the responsibility for the track, and Christian Brantschen, living in Celerina, has been occupied with it from 1990.

Construction of the track begins in the end of November and lasts about three weeks, and $15,000 \mathrm{~m}^{3}$ of snow and $7000 \mathrm{~m}^{3}$ of water are needed. There is a welldefined order of construction. Snow laying starts from the Sunny Corner curve to the Horse-Shoe curve, then goes to the Bridge Corner, turns into curves Martineau and Portago and ends on the finish line. Construction of the section from the start to the Sunny Conner happens after that. The records on the St. Moritz are not fixed, because its form each year may slightly vary. However, its official length is always the same- $1722 \mathrm{~m}$, the average slope is $8.14 \%$, and its difference in levels equals $130 \mathrm{~m}$. The general plan of the bobsleigh track in Switzerland between St. Moritz and Celerina is found on the webpage at: http://bobskesan.ru/track/st-moritz/\#har (BobskesanNd).

\section{Geometrical Characteristics and Technological Elements of Sporting Performance}

All modern tracks correspond to established technical criteria. Bobsleigh competitions for two- and four-man bob are held on tracks that can differ not only in overall parameters, the cross-section and radiuses of the curves, but also in total length. The length of the bob run is between 1200 and $2000 \mathrm{~m}$, the slope angle is about $8-15 \%$, and the number of curves is not less than thirteen. Tracks are designed to take into account the sequence of the technological elements of the sporting performance and are composed of the three main areas:

- the first area is "acceleration" with a maximal gradient on the natural slope of the land, with the length of 350-400 m and a limited number of sports items;

- the second area is "maximum performance" with the main sports elements (curves); the slope for all disciplines is not more than $15 \%$, the length is 800-850 m;

- the third area is "active finish" with a limited number of sports items; "labyrinth" and a slowing down part are planned here, the slope of the section is below the average, the length is $350-400 \mathrm{~m}$.

There are two sets of regulated sports items (types of curves), meeting international requirements,- - basic and complementary (these have appeared in recent years). The basic set includes: left turn $\left(17^{\circ}-19^{\circ}\right)$, right turn $\left(17^{\circ}-19^{\circ}\right)$, S-shaped element (combination of two curves), "hairpin", which is the curve with a turn of $180^{\circ}$, and "labyrinth", which is a combination of three or more bends (leftright-left, or vice versa) with the angles turned between $5^{\circ}$ and $17^{\circ}$, and where the length of the straight piece is not less than $50 \mathrm{~m}$. Complementary elements are: double curves (two consecutive left or right turn curves with a minimum straight insertion piece between them), "ring", which is the turn with a change of direction up to $270^{\circ}$, "gyroscope", which is the turn with a change of direction up to $360^{\circ}$, "omega", which is the combination of three or more curves with a turn in the range 
of $200^{\circ}-270^{\circ}$, "serpentine road", which is the combination of a few turns with a change in the direction of each within $170^{\circ}-180^{\circ}$, "falling", which is the bend the center line of which is perpendicular to the contour lines of geodetic underlay, and "comma", which is a single rotation with the change of direction in the range of $3^{\circ}$ $15^{\circ}$. The number of elements depends on the function of the track and terrain. The minimum number of bends is 13 (the track in Königssee, Germany), the maximum is 20 (Lake Placid, USA) (see Fig. 3).

$\diamond$ EXPANSION JOINT

\begin{tabular}{|c|c|c|c|c|}
\hline $\begin{array}{c}\text { NUMBEER } \\
\text { OF SECTION }\end{array}$ & $\begin{array}{l}\text { STATION } \\
\text { BEGIN OF } \\
\text { SECTION }\end{array}$ & $\begin{array}{l}\text { STATION END } \\
\text { OF SECTION }\end{array}$ & $\begin{array}{l}\text { LENGTH OF } \\
\text { SECTION }\end{array}$ & LOCATION \\
\hline & $|n|$ & $|m|$ & $\mid=1$ & \\
\hline $\mathbf{s} 100$ & .11 .00 & 62.00 & 73.00 & BOB START \\
\hline s101 & 6200 & 129.00 & 67.00 & CURVE C1 \\
\hline s102 & 129.00 & 19800 & 6900 & CURVE C2 \\
\hline s103 & 198.00 & 28500 & 87.00 & CURVE C3 \\
\hline s104 & 285.00 & 34200 & 57.00 & CURVE CA \\
\hline S105 & 342.00 & 449.00 & 107.00 & CURVE C5 \\
\hline s106.1 & 449.00 & 481.00 & 3200 & CURVE C6 \\
\hline S106.2 & 481.00 & 573.00 & 9200 & CURVE C6 \\
\hline S107 & 573.00 & 668.00 & 9500 & CURVE C7/CB \\
\hline $\mathbf{s} 109$ & 668.00 & 780.00 & 11200 & CURVE C9 \\
\hline s110.1 & 780.00 & 84200 & 6200 & CURVE C10 \\
\hline s110.2 & 842.00 & 924.00 & 8200 & CURVE C10 \\
\hline s111 & 924.00 & 1026.00 & 102.00 & CURVE C11 \\
\hline S112-S113 & 1026.00 & 1063.00 & 37.00 & CURVE C12/C13 \\
\hline s114 & 106300 & 1160.00 & 9700 & CURVE C14 \\
\hline S115 & 116000 & 1240.00 & 8000 & CURVE C15 \\
\hline S116.1 & 1240.00 & 127200 & 3200 & CURVE C16 \\
\hline S116.2 & 1272.00 & 1364.00 & 9200 & CURVE C16 \\
\hline S117.1 & 1364.00 & 1436.00 & 7200 & CURVE C17 \\
\hline S117.2 & 143600 & 150800 & 7200 & CURVE C17 \\
\hline s118 & 150800 & 158000 & 7200 & OUTRUN 1 \\
\hline s119 & 158000 & 165200 & 7200 & OUTRUN 2 \\
\hline $\mathbf{s 1 2 0}$ & 165200 & 1729.00 & 77.00 & OUTRUN 3 \\
\hline $\mathbf{s} 121$ & 172900 & 1761.00 & 3200 & $\begin{array}{l}\text { CURVE C18 } \\
\text { OUTRUN } 4\end{array}$ \\
\hline $\mathbf{s 3 0 0}$ & 1761.00 & 1800.00 & 3900 & SAFETY AREA \\
\hline $\mathbf{5 2 0 0}$ & .23 .00 & .11 .00 & 1200 & PREPARATION AREA \\
\hline S201 & 1200 & 62.00 & 50.00 & MEN START \\
\hline S202 & $\$ 200$ & 62.00 & 20.00 & JUNIOR START 1 \\
\hline S203 & 104.00 & 166.00 & 6200 & LADY START \\
\hline S204 & 166.00 & 198.00 & 3200 & LADY START \\
\hline S205 & 492.00 & 505.00 & 1300 & JUNIOR START 2 \\
\hline S206 & 656.00 & 668.00 & 1200 & PRACTICE START \\
\hline $\mathbf{S 2 0 7}$ & 170500 & 1705.00 & 0.00 & AREA WEIGHT HOUSE \\
\hline & \multicolumn{2}{|c|}{ TOTAL LENGTH } & 2012.00 & \\
\hline
\end{tabular}

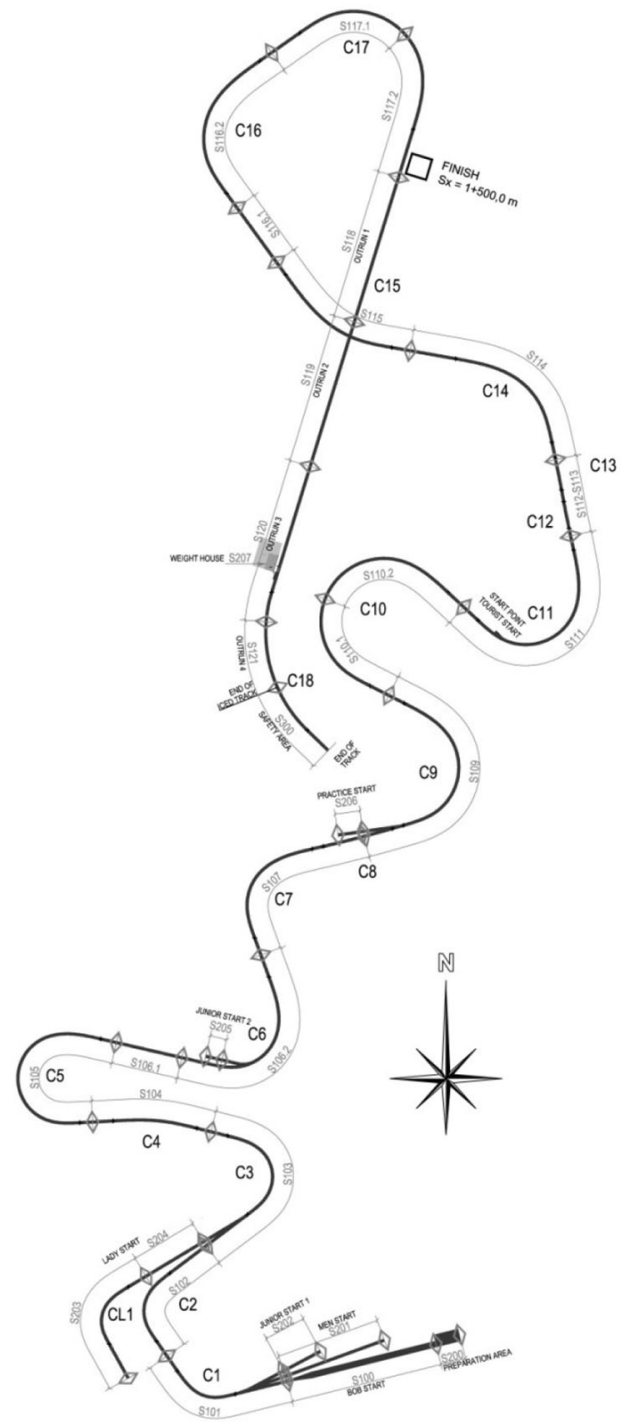

Fig. 3 Geometry of the bobsleigh track in Sochi. Author's original contribution 
The start area on the upper part of the track includes bends with small angles of rotation taking into account the acceleration of a sportsman. In the area "maximum performance", some turns are calculated on the basis of acceleration tolerance: for luge-4.5 g-force, for bobsleigh-4.0 g-force, and the duration of its action must not exceed $t=3 \mathrm{~s}, 1 \mathrm{~g}$-force $=9.80665 \mathrm{~m} / \mathrm{s}^{2}$. Maximum speed on the track can be no more than $117.6 \mathrm{~m} / \mathrm{s}$. It is only permitted to create 1 or 2 bends with such maximal accelerative forces on the track. In the "active finish" area of the track, simple bends are placed, their main function being to ensure the secure braking of the system. It is obligatory to erect counter-slope in the finish area for naturally braking bobsleds and skeletons.

Each curve consists of three parts: entry, radial section and exit. Entry and exit provide a smooth connection between a straight section and a radial in the 3-m space. The length of the entry and exit depends on the calculated input speed and the altitude of system on the radial part of the bend. The rise height of the system depends on the radial cross section of a bend. Entry and curve, calculated as a surface, provide bumpless transfer of system from a state of relative calm in the weightlessness with an overload. The athlete experiences increased overload with the entry. The exit from the radial part of a bend is calculated as a smooth curve, similar to the entry, but in reverse order. Radiuses and angles of rotation are not repeated in the plan of the tracks of any function. On international-class tracks the radial part that is more than $12 \mathrm{~m}$ may be calculated with variable curvature in plan and in cross section (see Fig. 4).

The length of the straight segments of the track of an active area relative to the total length of the way for sledding is $25-30 \%$, and for bobsleigh it is $40 \%$. The length of the straight parts connected with bends depends on the speed parameters; the minimum length of the tracks for sledding can be up to $2.0 \mathrm{~m}$ or completely absent. On the bobsleigh track the minimum straight length can be $9.5 \mathrm{~m}$ with the velocity of $23.8-26.2 \mathrm{~m} / \mathrm{s}$. By the speed increasing up to $32 \mathrm{~m} / \mathrm{s}$ the minimum length of a straight part is $15.0 \mathrm{~m}$. The high-speed part of the track is considered as such, where the average speed is increased by $10 \%$. The maximum velocity of the heavy four-man bobsled can exceed $v=150-160 \mathrm{~km} / \mathrm{h}=44.4 \mathrm{~m} / \mathrm{s}$.

The longitudinal profile conjugation of the track is performed by a smooth radial curve with a radius no less than $80 \mathrm{~m}$. The braking part situated at the end of the track is designed with a reverse slope, the length of 90-120 m and with a horizontal platform at the end of the track to reduce the speed. The whole of the track is designed, as a rule, without the reverse slope, with the exception of the braking part.

The bob run is a complex surface of alternating straight sections and angled prismatic and curved canal-type surfaces. The track trough is built using the kinematic method, moving along the guide axis the generating line by a variable form (such as the frame) lying in a vertical plane. The plane of the motioned frame remains orthogonal to the horizontal projection of the track axis. The law of generatrix shapes and sizes variation depends on the curvature changes of the length and in terms of speed on the section of the track. 

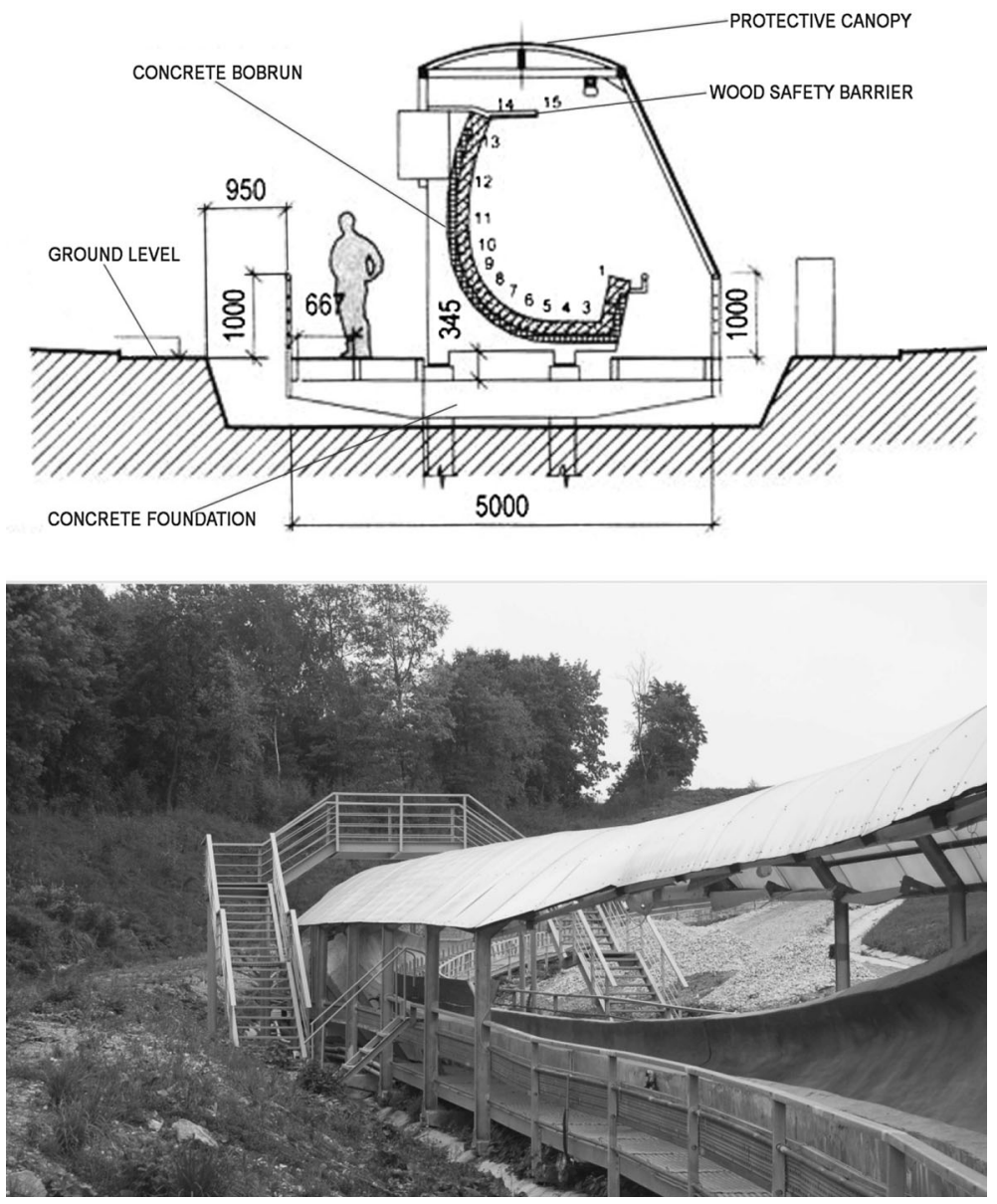

Fig. 4 Bobsleigh track in Paramonovo, Moscow region. Above the radial cross section in the highest point of the curve. Author's original contribution. Below pedestrian bridge overpass. Author's photo, August 2010

The track design includes three stages:

- the first is the plotting on the geodesic underlay of the polyline defining the direction of the track. The tops of the polyline are fixed in the rectangular coordinate system of the geodetic layout;

- the second is the calculation of the circle radius and the length of the transition curves at the top of the polyline, which are determined depending on the speed parameters;

- the third is when the projecting axis plan is taken as a guide for cylindrical surface.

The line of its intersection with the ground is the basis of the design of the second projection of track axis - the profile sweeping of the plan line. The speed 
calculation is carried out simultaneously with the generation of the axial line. The bobrun surface is calculated by the two axis projections (plan and profile) in combination with dynamic analysis of parameters obtained during the motion of the system. The bobrun longitudinal profile is the project line and at the same time serves as a guide to shaping its surface on the basis of dynamic analysis. The axis of the bobrun on the plan and on the longitudinal profile is composed of individual straight pieces intersected at different angles and conjugated by curved elements. During the design of the bobrun, as well as adjacent buildings, a unified coordinate system with three points of reference is applied to the horizontal projection of the track axis: the first is the reference point from the starting point of four-man bobsled $(0 x)$, the second coordinate is the distance from the entry point into the curve and the number of the curve on which this point of the track is, the third coordinate is the elevation level. The value of the inlet velocity in curves and in their cross sections are calculated in accordance with the laws of physics by specialized companies that have licenses for this type of activity. One of the well-known companies producing the dynamic calculations and design of many world bobsleigh tracks is the Ingenieurbüro Gurgel (IBG) found in 1993 by Udo Gurgel in Leipzig, Germany.

In the world today there are 18 bobsleigh complexes that meet international requirements and work in normal mode, 12 complexes that operate on an exclusive request and 2 complexes that are in the construction stage. Three tracks with 14 curves are selected for comparison (Fig. 5). The track geometry of Nagano begins as if it starts with the letter ' $N$ ' and forms the typical serpentine descent tape from the start area to the finish area, also ending with the letter ' $N$ '. The track of Winterberg in its geometry has a peculiar letter ' $\mathrm{W}$ ' with twisted loop in the center. The track of Innsbruck-Igls in its geometry has a central loop, and is characterized by the finishing section of track, which runs underground and, coming up, forms into its composition a distinctive point of the letter ' $\mathrm{i}$ ', with which the name of the city begins. Thus, each track is a unique structure with its own architecture and its own geometry, symbolically underlining its geographical location despite its identical geometric components.

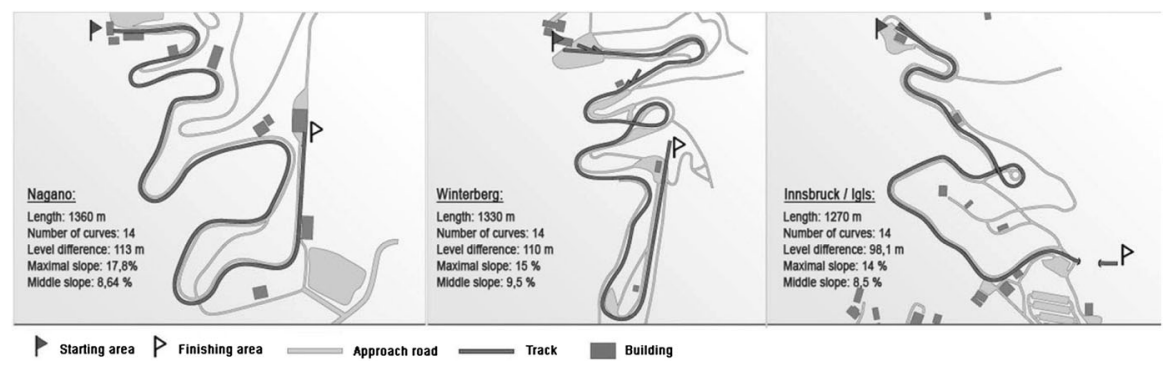

Fig. 5 Bobsleigh tracks in Nagano, Winterberg and Innsbruck-Igls. Analytical schemes are made by the author 


\section{Bobsleigh Track in Architectural Complex}

The bobsleigh track, in accordance with the classification (Klassifikatsiya sportivnykh sooruzheny), is a separate outdoor sports facility used for competitions and training for bobsleigh, skeleton and sled. Built as a special architectural project, it is the main structure, along side which service buildings and infrastructure for spectators are placed. Artificial tracks are built of concrete. Ice freezes on the concrete bobrun surface with the help of special technology using ammonia or carbon dioxide. The plans of sport complexes, as well as the geometries of the tracks differ from each other. Auxiliary buildings and facilities are designed depending on the configuration of the main track, the location of the start and finish points, and the homestretch (see Fig. 6).

The slope should be to the north or north-east; the optimum is to lay the track on the watershed slope. The average natural slope for the sled tracks is $17-22 \%$, for the combined and bobsleigh tracks it is $14-19 \%$. The slope with pine forests, with a smooth relief, without ravines and hills is optimal. Designing the track line, great

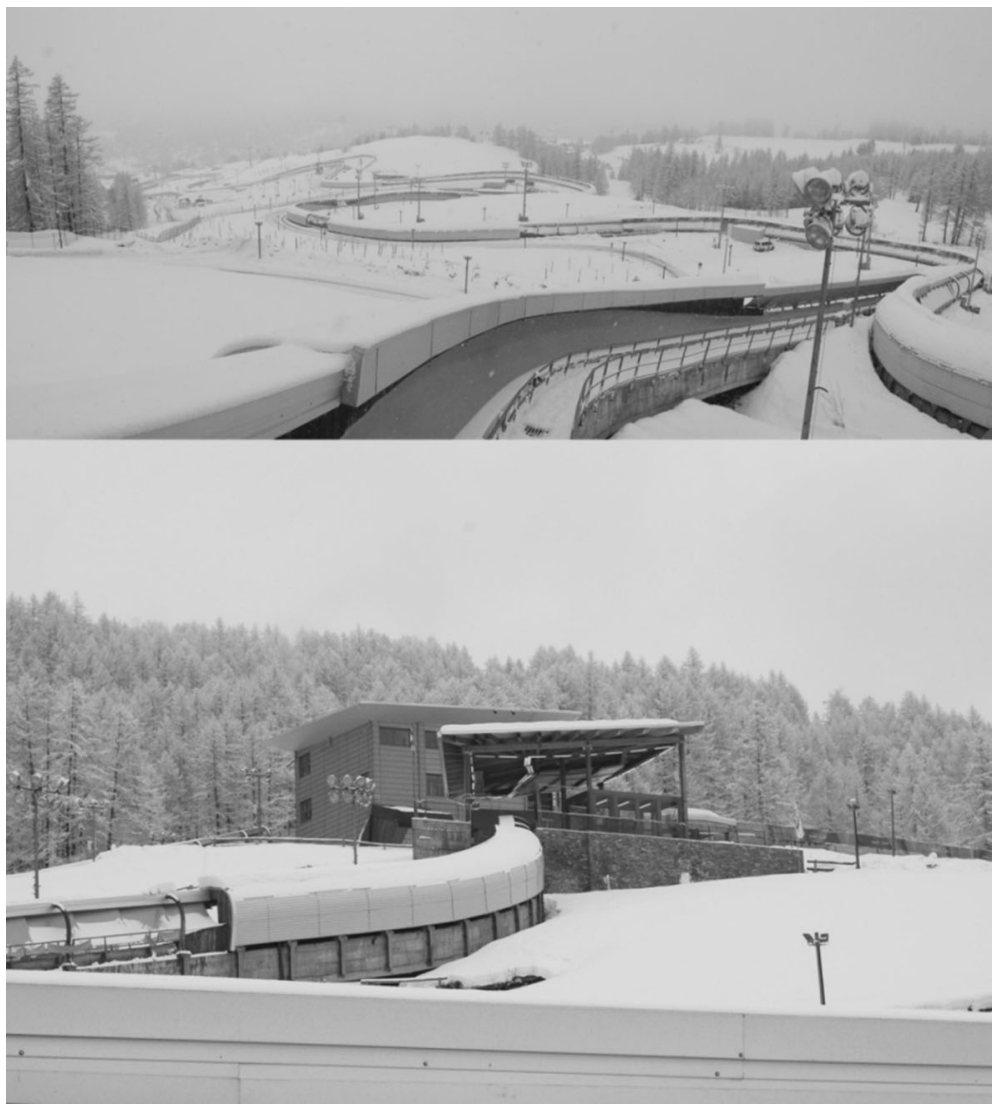

Fig. 6 Bobsleigh track in Turin, Italy. Author's photo, February 2011 
importance is given to the existing environment in which it is planned to allocate the object: the existing trees and green arrays are preserved as much as possible. The constancy of the snow should be preferably not less than 4 months; the average winter temperature must be from -12 to $-25^{\circ} \mathrm{C}$. It is reasonable to design a track on the plot of land that allows the buildings to be arranged in the sequence of the technological elements of the sporting performance. Along the bobrun are placed a refrigerating station, lighting appliances, master clock system, communication lines, water supply lines, volume constructions for the servicing of training and competition, and spectator stands and other structures.

One of the newest bobsleigh tracks was built in Russia in 2012 for the XXII Winter Olympic Games in Sochi. Sliding Center 'Sanki' is its official name. Currently, it is used as a national training center. The sports complex is situated $60 \mathrm{~km}$ to the north-east of Sochi, near the Krasnaya Polyana, at a ski resort, AlpikaService, on the northern slope of the Aibga Ridge. The plot has an elongated shape; the location is hidden from direct sunlight and protected from winds.

The general plan of the sports complex was elaborated by NPO Mostovik [Proyekt: Sanno-bobsleynaya trassa $s$ inzhenernoy zashchitoy $i$ vneploshchadochnymi setyami elektrosnabzheniya, vodosnabzheniya $i$ kanalizatsii (proyektnyei, izyskatelskiye raboty, stroitelstvo) 2010-2014], according to the masterplan scheme designed by Canadian firm Planimetrix Design Group Inc. The main structure is the bobsleigh track (Figs. 7, 8), located from south to north along the entire plot of land, taking into account the existing topography, prevailing wind direction, and orientation to the cardinal points. The architectural planning placement of the track on this plot of land was not by chance-all turns, ups and downs of the main sports facility needed for the Olympic Games and other international competitions in luge sports repeated the three-dimensional formation of the existing earths' surface, as if mountain streams continue their movement towards the florid planning structure of the bobsleigh tracks' "bed". The landscape relief is enough, compounded with a difference between elevations of $190 \mathrm{~m}$ from 670.0 to $860.0 \mathrm{~m}$. The main task in the organization of the relief was the maximum possible preservation of existing overgrown trees and the present terrain with the

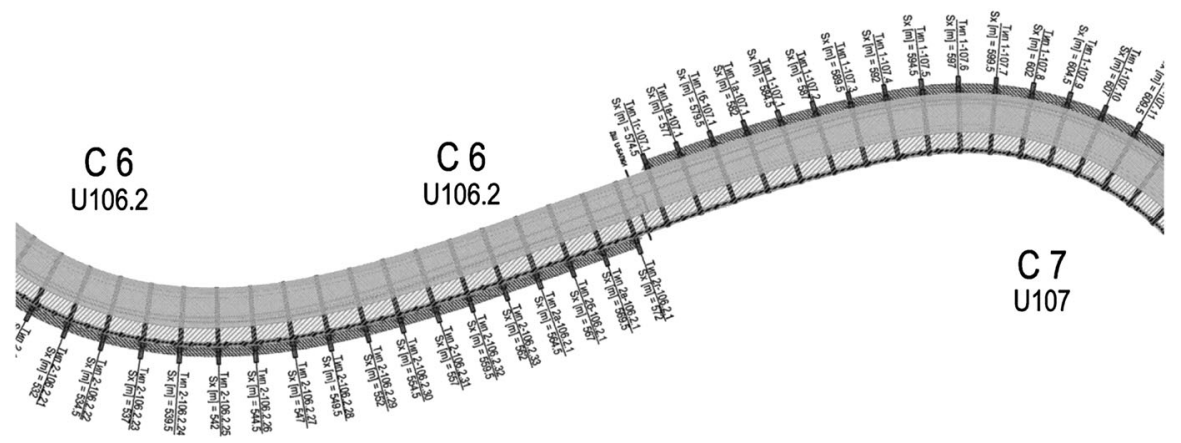

Fig. 7 Fragment of bobsleigh track in Sochi. Approved design 2010-2012. Author's original contribution 

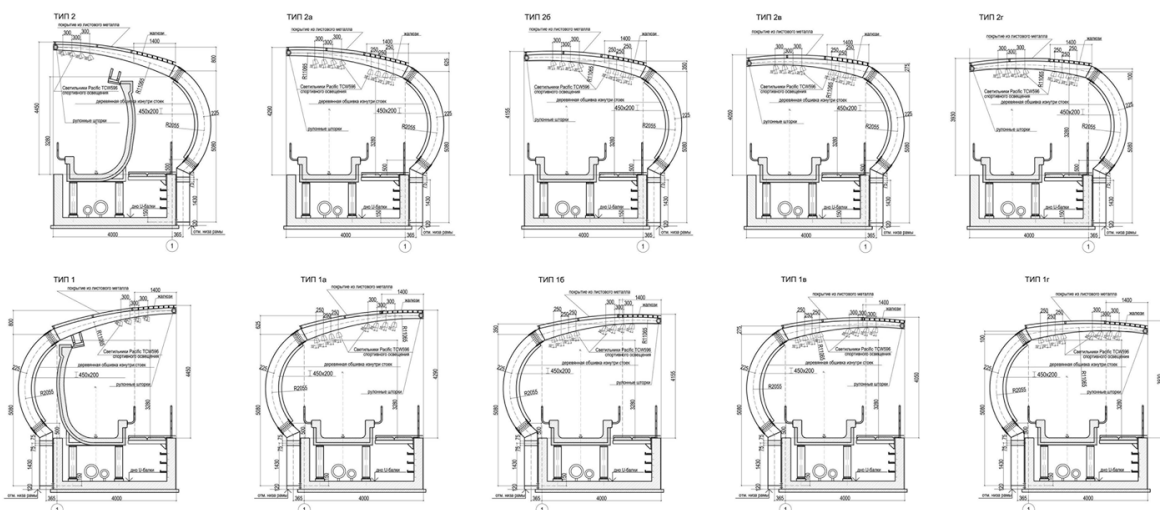

Fig. 8 Protective roofs of bobsleigh track in Sochi. Approved design, 2010-2012. Author's original contribution

optimal value of the construction project. The relief was realized by using slopes to reduce the financial costs; the earth-retaining walls were designed and constructed in the places where it was not possible to solve the terrain differences by using slopes. The spectator area is terraced; arrival at the terraces is from the driveways along the track. The connection between grounds for spectators is realized by staircases with dimensions of steps $12 \times 40 \mathrm{~cm}$ and a width of $3 \mathrm{~m}$. The lifting of the athletes and coaches to the start zones of the bobsleigh track is carried out by surface transport. Next to the track there is a road with a width of $3.75 \mathrm{~m}$ that serves for technical support and is suitable for the passage of light trucks; this road is also used for pedestrian movement. The road that runs next to the track becomes wider by up to $5 \mathrm{~m}$ on the most spectacular places with a higher concentration of spectators. The complex has a capacity of 9000 spectators, including 1000 seats and 8000 standing places.

An artificially refrigerated concrete bobrun, designed for sports competitions in bobsleigh, skeleton and luge, largely repeats the existing slope of the terrain. The bobrub length equals $1814 \mathrm{~m}$, with an effective slope of $1450 \mathrm{~m}$. The Sochi track was designed by taking into account the maximum safety of the athletes; it has three counter-slopes to provide reduction of speed in a natural way, the sizes of which do not exceed $20 \%$.

To maintain the track against the sun and atmospheric precipitation a protective canopy structure, which is made of sheet metal, was designed and implemented along the whole facility. The track is also protected from the outside of the curves by wood sheathing mounted on pillars of the canopy. The radial shape of the pillars and the construction of the sheathing were dictated by reasons of athlete's safety during their passage of the track. Lighting, technological and translational cameras, monitors and other equipment are attached under the canopies. Roller blind mechanisms are attached to the canopies along the open front side of the track. In bad weather and bright sunshine the unrolled blinds protect the insides of the curves and the straight parts of the bobrun. 
Stationary and mobile buildings and structures servicing the track are located along it, in accordance with the sports technologies. The stationary buildings and facilities are: men's start building, women's and double-sled start building, finishtower building, the weight house, track operator building, ammoniac station building, fire station building, the integrated control center building, the buildings of security check-point, underground passages and pedestrian bridge overpasses. There are also squares to accommodate the spectators, the Olympic family, media, television, and official ceremonies, station 'Tetra', parking for transport, transformer substation, pumping plants, water reservoirs, etc. A unit of high profile cabs for commentators to ensure the broadcast of the competitions during the Olympic Games was established. Near to the low part of the track, between curves C15 and $\mathrm{C} 16$, ten monolithic concrete platforms with dimensions of $4 \times 6 \mathrm{~m}$ to accommodate fixed cameras are located on the territory. The altitude marks of the platforms are equal to the altitude marks of the adjacent territory. Mobile facilities are represented by canopies, containers and tents to accommodate sports teams, the Olympic family, a first-aid post, security, public catering, sale of souvenirs, tribunes for spectators, etc.

Sledding and bobsleigh are one of the most spectacular winter sports, so there is a need to ensure the highest level of visual perception of the competition. Spectator tribunes with standing places are located along the track to see the sportsmen and women pass the curves.

Tribunes with seating places are located in the main entertainment points: in the area of the bob-start building and in the area of the weight house (Fig. 9). One of the main spectator areas is located inside the finishing loop and it was arranged on the basis of artificial terracing so that from this place the most comfortable review of both the finish line and the last turn is possible. Spectator access to the territory is through the passages under the track. The complex has two underground and two
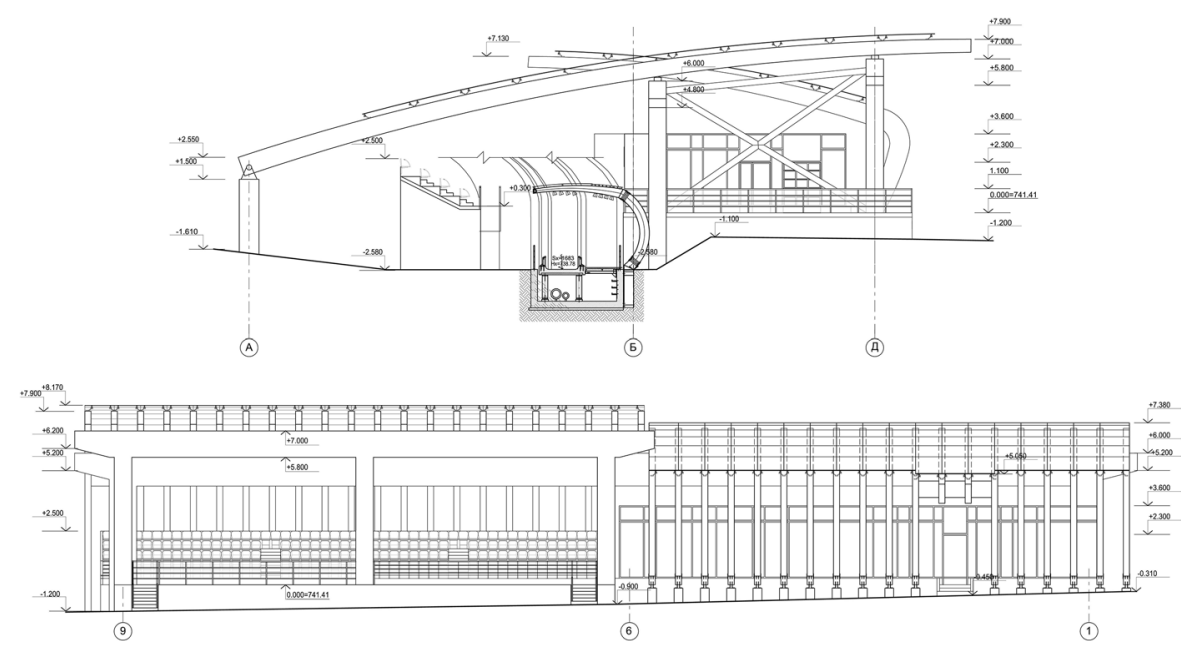

Fig. 9 Bobsleigh track in Sochi. Façades of the Weight house designed in 2010-2012. Author's original contribution 
bridge crossings for better pedestrian and transport accessibility; these are arranged to ensure unimpeded passage of spectators to any part of the track, as well as of minibuses and special machinery.

The architecture of the complex organically combines with the existing natural landscape. Stationary buildings were divided into two groups based on their functions and this is visually reflected in their spatial-volumetric compositions. The main buildings, adjacent to the track (men's start building, women's and doublesled start building, finish-tower building, the weight house, and the track operator building) were designed in such a way that their shapes are connected with all areas of the track creating one integral composition. Laconic glass volumes are covered with curved canopies, made of glu-lam and covered with a special transparent polycarbonate. The shape and material of protective canopies of buildings, despite their expression, are not contrary to the surrounding landscape. They merge into the general movement of the entire structure of the complex, highlighting the key points of these winter kinds of sport with their architectural form, and the associations that send the viewer to the origins of luge, namely, the ancient wooden sled with curved runners.

The facilities of the technical area (ammoniac station building, fire station building, and the integrated control center building) are located at the entrance to the complex. The volumes of these buildings are inserted into the existing steep terrain, they "look out" from the ground with one, or maximum two, façades and, going on the second plan, create a uniform background and dissolve in the natural mountain landscape.

An aluminum stained-glass system filled with energy-efficient glazing was applied in the building envelopes. The external surfaces of the reinforced concrete walls of buildings were treated with colorless or decorative protective coatings. The covering of start platforms, galleries, and the platform for preparation of the sleds was made of terrace boards on boarding joists. Stainless steel constructions were used in the fences of galleries, platforms and stairs. The spatials way bracing between concrete structures was realized from metal and covered with weatherresistant enamel. The interior decoration was carried out in accordance with the technological functions of the rooms.

\section{The Use of the Track in the Off Season: Conclusions}

The bobsleigh track is one of the most complex objects in terms of adapting it for any other function. Very often, due to lack of funding, these grandiose constructions fall into decline and are abandoned. The XIVth Winter Olympic Games were held in Sarajevo in 1984. The bobsleigh track, with a length of $1300 \mathrm{~m}$, was specifically built in the Yugoslav capital two years earlier for that event. The competitions were carried out, the sets of medals were played, and after the military operations in the early 1990s in Sarajevo the bobsleigh track became worthless and was abandoned. The first Soviet training bobsleigh track, built in 1981 on the hill Tuganak next to Bashkir city Meleuz was also neglected. There, the first all-union competition and national team training were carried out. Soviet engineers built it by intuition, 
without ready-made drawings of such facilities. The track was dangerous, uneven, with large differences of speeds, and it was not rebuilt because of the high cost (see Fig. 10).

The bobsleigh track with natural freezing ice in the vicinity of St. Moritz mentioned earlier, as shown in the presentation video on the official website of the track, is used in the summer period to play golf, for bicycle lanes, for grasslands and as pastures for sheep. A car road between St. Moritz and Celerina is in immediate proximity to the track along the part named Via Maistra. During the winter season this road is partly blocked. In March, the stabilizations of the track are removed, and the snow slowly melts until June. In summer it is almost impossible to imagine that this place is also used for the bobsleigh track.

Some literary sources (Aristova 1999) note that it is desirable to site the bobsleigh track by choosing an area next to rivers, lakes, and ponds, in order to use them in summer seasons for other kinds of sport and recreation.

In 2016, from 18 to 21 August, the bobsleigh track of Sochi hosted the international competition in downhill racing on rollers and longboards, Beton on Fire. The event was organized by the International Association of rollers (WISAWorld Inline Skaters Associations, France). Athletes from Germany, France, Switzerland and Russia participated in the tournament in Krasnaya Polyana. Similar competitions have been held at the bobsleigh complexes in Europe (including Germany, Latvia, and France) every year since 2009. These events, which involve the best athletes from around the world, receive broad support, and WISA plans to expand the geography of its own annual competition (Canada, Norway, Russia, and USA) and increase their intensity (Kulakov 2016).

Many tracks have tourist starts in their construction and offer rides in a bobsledtaxi for all comers. There are tracks in Sigulda (Latvia), Igls (Austria), Calgary (Canada), Lillehammer (Norway), Lake Placid and Salt Lake City (USA) and La

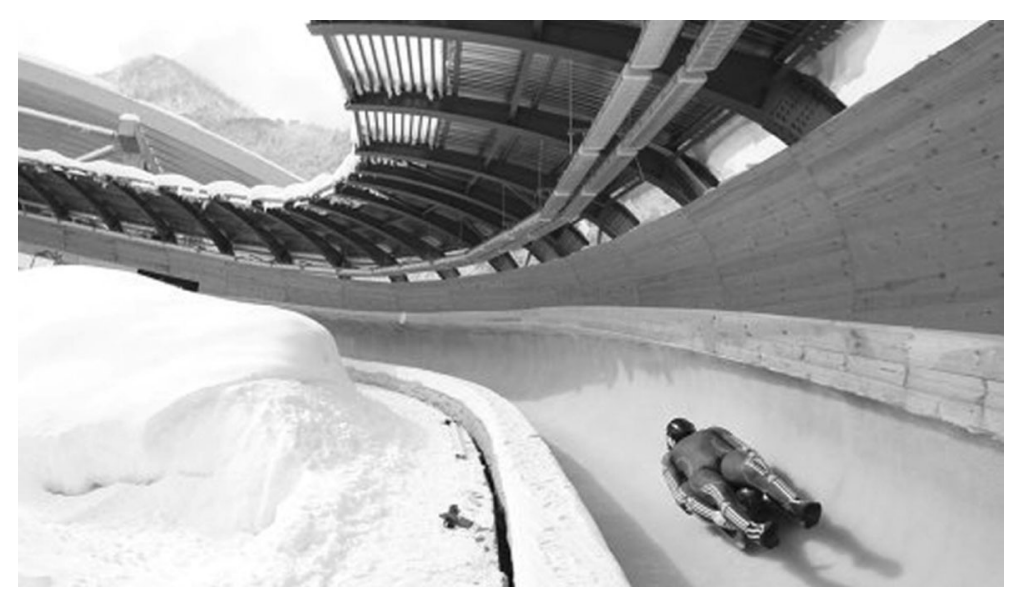

Fig. 10 Bobsleigh track in Sochi. Above the use of the bobsleigh track during the winter seasons. Author's photo, March 2012 
Plagne (France). Thus, these unique facilities gradually win popularity both in sports and in the tourism industry.

\section{References}

Aristova L. V. 1999. Fizkulturno-sportivnye sooruzheniya [Physical training and sport facilities] Moscow: SportAkademiya - Press.

Bobskesan (in Russian), Nd. Olimpyskaya trassa v Sankt-Moritse [Olympic track in St. Moritz]. http:// bobskesan.ru/track/st-moritz/\#har (accessed 10 November 2016).

IBSF. 2015. International Bobsleigh Rules 2015 -IBSF http://www.ibsf.org/images/documents/ downloads/2015_International_Rules_BOBSLEIGH.pdf (accessed 10 November 2016).

Klassifikatsiya sportivnykh sooruzheny [Classification of sports facilities]. http://www.thsport.ru/ poleznyie_stati.html (accessed 10 November 2016).

Kulakov S. 2016. V Sochi proshli sorevnovaniya po spusku na rolikakh i longbordakh na bobsleynoy trasse "Beton on Fire". [The competition Beton on Fire in downhill on rollers and longboard took place on bobsleigh track in Sochi]. http://fotoserg.livejournal.com/204889.html (accessed 10 November 2016).

Proyekt Sanno-bobsleynaya trassa s inzhenernoy zashchitoy $i$ vneploshchadochnymi setyami elektrosnabzheniya, vodosnabzheniya i kanalizatsii (proyektnyei, izyskatelskiye raboty, stroitelstvo). [Project Bobsleigh track with engineering support and outside networks of electricity, water supply and sanitation services (design and survey works, construction)] 2010-2014. Moscow. OOO NPO 'Mostovik'.

Mariya Komarova is an architect who graduated from Ulyanovsk State Technical University in 2003 and qualified as an architect-designer in the Design of Architectural Environment. The topic of her graduation project was based on the reconstruction of the historical city center of Ulyanovsk. Until 2006 she worked as an architect under the Ministry of Culture of the Russian Federation. In 2005 she became a member of the Architects Union of Russia. From 2006 to 2014 she lived in Moscow, where she took part in the project of restoration, reconstruction and technical equipment of the Bolshoi Theater complex of buildings. There she worked also at the Olympic bobsleigh track in Sochi in 2010-2012, learning Italian language in her free time. In 2014 she started her Ph.D. in Architectural and Landscape Heritage at the Politecnico di Torino and during her studying participated in a few international scientific conferences. 